\title{
Sequencing the exons of human glucocorticoid receptor (NR3C1) gene in Han Chinese with high-altitude pulmonary edema
}

Hui Du ${ }^{1,2}$, Jing Zhao ${ }^{1}$, Zhanhai Su', Yongnian Liu ${ }^{1}$ and Yingzhong Yang ${ }^{1,2^{*}}$

\begin{abstract}
Background: High-altitude pulmonary edema (HAPE) is a serious acute mountain sickness that mainly occurs in non-acclimatized individuals after rapid ascent to high altitude. The precise etiology of HAPE remains unclear. This study aimed to investigate whether NR3C1 gene polymorphism is associated with the susceptibility to HAPE.

Methods: The exons of NR3C1 gene were sequenced by a ABI 3730 DNA analyzer in 133 HAPE patients and matched 135 healthy Han Chinese controls from the Yushu area in Qinghai (the altitude greater than $3500 \mathrm{~m}$ ).

Results: DNA sequencing showed the heterozygous substitutions at codon 588 (rs6194) in exon 6 and 766 (rs6196) in exon 9 of NR3C1 gene. The genotypic distributions and allelic frequencies of NR3C1 SNP rs6194 showed significant differences in two groups $(P<0.05)$. The frequencies of the $C$ allele were significantly higher in the HAPE group than in the control group $(P<0.05)$ with an odds ratio of 3.009 (95\% Cl=1.250-7.244). There were no differences in genotypic and allelic frequencies in rs6196 polymorphism between the two groups.
\end{abstract}

Conclusions: NR3C1 gene rs6194 polymorphism is correlated with HAPE susceptibility. CC genotype and C allele of rs6194 polymorphism might increase the risk of HAPE in Han Chinese.

Keywords: NR3C1, Exon, SNP, HAPE, Susceptibility

\section{Background}

High-altitude pulmonary edema (HAPE) is noncardiogenic pulmonary edema that usually occurs in rapidly ascending non-acclimatized individuals within the first week after arrival at altitudes above $2500 \mathrm{~m}[1,2]$. HAPE tends to be associated with exaggerated pulmonary hypertension and is defined as a non-inflammatory hemorrhagic pulmonary edema [3]. Circulating inflammatory markers are upregulated at high altitude, and HAPE patients show markedly elevated inflammatory markers in the bronchoalveolar lavage fluid. Thus, it is speculated that hypoxia-induced inflammation at high

\footnotetext{
* Correspondence: yingzhong-yang@hotmail.com

${ }^{1}$ Department of Basic Medical Sciences, Medical College, Qinghai University, Xining 810001, Qinghai, China

${ }^{2}$ Research Center for High Altitude Medical Sciences, Medical College,

Qinghai University, Xining 810001, Qinghai, China
}

altitude may contribute to the development of HAPE $[4,5]$.

NR3C1 (Nuclear Receptor Subfamily 3, Group C, Member 1) gene is located on chromosome 5q31-q32 and encodes human glucocorticoid receptor (GR). Glucocorticoids (GCs) bind to GR and translocate to the nucleus where they interact with glucocorticoidresponsive elements of different genes and regulate transcription. GCs inhibit the production of proinflammatory cytokines and stimulate the production of anti-inflammatory cytokines [6]. Variants in NR3C1 gene may contribute to the spectrum of GC responses in different diseases [7]. Therefore, we performed a genetic sequencing and screening in HAPE patients to investigate possible association of genetic variations of $N R 3 C 1$ gene with HAPE. 


\section{Methods}

\section{Subjects}

HAPE patients (HAPE) had been hospitalized during 2010 to 2017 in Yushu city (3760 m) of Qinghai province. The patients were diagnosed with HAPE based on the diagnostic criteria [8]. Healthy controls (Non-HAPE) were enrolled from the same area, with matched age, gender, and workplace (Table 1). These subjects had not suffered from HAPE or any other mountain sickness after reached at least 3 months. One hundred thirty-three HAPE and 135 matched Non-HAPE were enrolled. This study was approved by the Ethics Committee of the Medical College of Qinghai University, and every subject signed written consent. All subjects were of Han Chinese ethnicity and had no blood relationship with any other enrolled subject.

\section{Sample collection and DNA extraction}

Five milliliters of venous blood samples was collected from each participant. Blood samples were anticoagulated by EDTA. Genomic DNA was extracted from blood by Gentra Puregene Blood Kit (Qiagen, 158389, Germany) according to standard procedures. DNA samples were stored at $-20^{\circ} \mathrm{C}$ until use.

\section{Exons PCR and sequencing}

The primers of NR3C1 gene (NG_009062) were designed by Primer3 (version 0.4.0) to encompass each exon except Exon 1. Exon 2 was divided into two parts due to its length (Table 2). The exons were amplified by PCR using Phusion ${ }^{\circledR}$ High-Fidelity PCR Master Mix (F532L, Thermo Fisher Scientific Inc.). PCR cycles consisted of denaturation at $96{ }^{\circ} \mathrm{C}$ for $1 \mathrm{~min}, 30$ cycles of $96{ }^{\circ} \mathrm{C}$ for $10 \mathrm{~s}, 60{ }^{\circ} \mathrm{C}$ for $30 \mathrm{~s}$, and $72{ }^{\circ} \mathrm{C}$ for $30 \mathrm{~s}$, and a final elongation at $72{ }^{\circ} \mathrm{C}$ for $5 \mathrm{~min}$. Amplified fragments were resolved on $1.5 \%$ agarose gels stained with ethidium bromide. PCR products were bidirectionally sequenced with a ABI 3730 DNA analyzer by Shanghai Generay Biotech Co., Ltd, and compared with the published sequence of NR3C1 gene.

\section{Statistical analysis}

SPSS software (version 17.0; SPSS, Inc, Chicago, IL, USA) was used for statistical analysis and $P<0.05$ was considered as statistically significant. Hardy-Weinberg equilibrium
(HWE) was used to assess the representativeness of the participants. Allele frequencies were calculated based on genotype frequencies in HAPE and Non-HAPE groups, and the intergroup difference was estimated with chisquare test. Odds ratios (ORs) and 95\% confidence intervals (95\% CIs) were used to evaluate the association between the variants and HAPE.

\section{Results}

We sequenced the exons 2 to 9 of NR3C1 gene in HAPE and Non-HAPE groups. DNA sequencing showed two single nucleotide substitutions at codon 588 in exon 6 (Fig. 1a) and codon 766 in exon 9 (Fig. 1b). We did not detect any differences in other exons. The variant in exon 6 was a silent $C$ to $T$ heterozygous change (CAC to CAT, both encoding histidine, synonymous codon). The variant in exon 9 was also a silent $\mathrm{T}$ to $\mathrm{C}$ heterozygous change (AAT to AAC, both encoding asparagine, synonymous codon). These polymorphisms had been deposited in dbSNP with the accession number rs6194 and rs6196, respectively. Genotype distributions of rs6194 and rs6196 polymorphisms did not deviate from HWE in HAPE and Non-HAPE groups $(P=0.754$ for rs6194 in HAPE group, $P=0.346$ for rs6194 in Non-HAPE group, $P=0.491$ for rs6196 in HAPE group, and $P=0$. 216 for rs6196 in Non-HAPE group).

Frequency distributions of rs6194 polymorphism in HAPE group were different from Non-HAPE group (Table 3). CC genotype was more frequently observed in HAPE group than in Non-HAPE group, indicating a significant association with HAPE risk $(P=0.008, \mathrm{OR}=$ $3.180,95 \% \mathrm{CI}=1.299-7.825)$. $\mathrm{C}$ allele frequency showed a significantly increased trend in HAPE group than in Non-HAPE group $(P<0.05)$ with an odds ratio of 3.009 (95\% CI $=1.250-7.244)$. There were no differences in genotypic and allelic frequencies in rs6196 polymorphism between the two groups (Table 4).

\section{Discussion}

Circulating inflammatory markers are known to be upregulated at high altitude [9]. Serum levels of IL-6, IL-6 receptor, and C-reactive protein increased in healthy volunteers who spent three nights at an elevation higher than $3400 \mathrm{~m}$ [4]. The climbers at $8400 \mathrm{~m}$ had severe hypoxemia with subclinical HAPE [10]. Moreover,

Table 1 Comparison of baseline data of two groups

\begin{tabular}{llllllll}
\hline Group & $n$ & Gender & Age (years) & HGB $(\mathrm{g} / \mathrm{dL})$ & $\mathrm{Hct}(\%)$ & $\mathrm{HR}(\mathrm{b} / \mathrm{m})$ & $\mathrm{SaO}(\%)$ \\
\hline HAPE-p & 133 & Male & $40.20 \pm 9.91$ & $157.24 \pm 15.24^{*}$ & $47.79 \pm 4.97^{*}$ & $109.73 \pm 14.85^{*}$ & $62.46 \pm 11.89^{*}$ \\
HAPE-r & 135 & Male & $40.92 \pm 5.15$ & $172.80 \pm 14.54$ & $50.74 \pm 8.15$ & $80.84 \pm 12.03$ & $88.85 \pm 4.17$ \\
\hline
\end{tabular}

Values were means \pm S.D.

HAPE- $p$ high-altitude pulmonary edema patients, $H A P E-r$ high-altitude pulmonary edema resistant (Control), $H G B$ hemoglobin, $H c t$ hematocrit, $H R$ heart rate, SaO ${ }_{2}$ oxyhemoglobin saturation

${ }^{*} P<0.05$ vs. HAPE-r 
Table 2 Amplification primers for NR3C1 gene exons

\begin{tabular}{|c|c|c|c|c|}
\hline Exon & Primer & Sequence & $\operatorname{Tm}\left({ }^{\circ} \mathrm{C}\right)$ & Length (bp) \\
\hline \multirow[t]{2}{*}{ 2-1 } & GR-EXON2-1F & 5'-TCGGATCAGGAAGATAATGTGA-3' & 60 & 728 \\
\hline & GR-EXON2-1R & 5'-GATCTCCAAGGACTCTCATTCG-3' & & \\
\hline \multirow[t]{2}{*}{$2-2$} & GR-EXON2-2F & 5'-AGACCAAAGCACCTTTGACATT-3' & 60 & 773 \\
\hline & GR-EXON2-2R & 5'-TTCCTACTTTCAAAAGGCCACT-3' & & \\
\hline \multirow[t]{2}{*}{3} & GR-EXON3-F & 5'-GCACTTGAAGCCAGAGTTCAC-3' & 60 & 342 \\
\hline & GR-EXON3-R & 5'-CACCCTGAGAAATGAAAACCA-3' & & \\
\hline \multirow[t]{2}{*}{4} & GR-EXON4-F & 5'-CAATACCTGTGGGTGTCTTGG-3' & 60 & 387 \\
\hline & GR-EXON4-R & 5'-TTCCCATTITATTGGGCAGT-3' & & \\
\hline \multirow[t]{2}{*}{5} & GR-EXON5-F & 5'-TTGAATAAACTGTGTAGCGCAGA-3' & 60 & 501 \\
\hline & GR-EXON5-R & 5'-CACCTGTATTCACCTGACTCTCC-3' & & \\
\hline \multirow[t]{2}{*}{6} & GR-EXON6-F & 5'-GACAGGGCTAATTGATCTCATTG-3' & 60 & 307 \\
\hline & GR-EXON6-R & 5'-ATCAGGAAAACATCAGCTGGTTA-3' & & \\
\hline \multirow[t]{2}{*}{7} & GR-EXON7-F & 5'-TTGCAAAACAAAACAAAAATGTG-3' & 60 & 384 \\
\hline & GR-EXON7-R & 5'-GGTGTCACTTACTGTGCCTTTCT-3' & & \\
\hline \multirow[t]{2}{*}{8} & GR-EXON8-F & 5'-GGATGACACAGTGAGACCCTATC-3' & 60 & 391 \\
\hline & GR-EXON8-R & 5'-TTGAACTCAAGCTATCACCAACA-3' & & \\
\hline \multirow[t]{2}{*}{$9 a$} & GR-EXON9a-F & 5'-GGGAATTCCAGTGAGATTGGT-3' & 60 & 459 \\
\hline & GR-EXON9a-R & 5'-AACTGCTTCTGTTGCCAAGTC-3' & & \\
\hline \multirow[t]{2}{*}{$9 \beta$} & GR-EXON9B-F & 5'-GTGTAACCCGGCTGGATAAAT-3' & 60 & 508 \\
\hline & GR-EXON9ß-R & 5'-TCTGCTTTCAAACAGCACCA-3' & & \\
\hline
\end{tabular}

Tm melting temperature
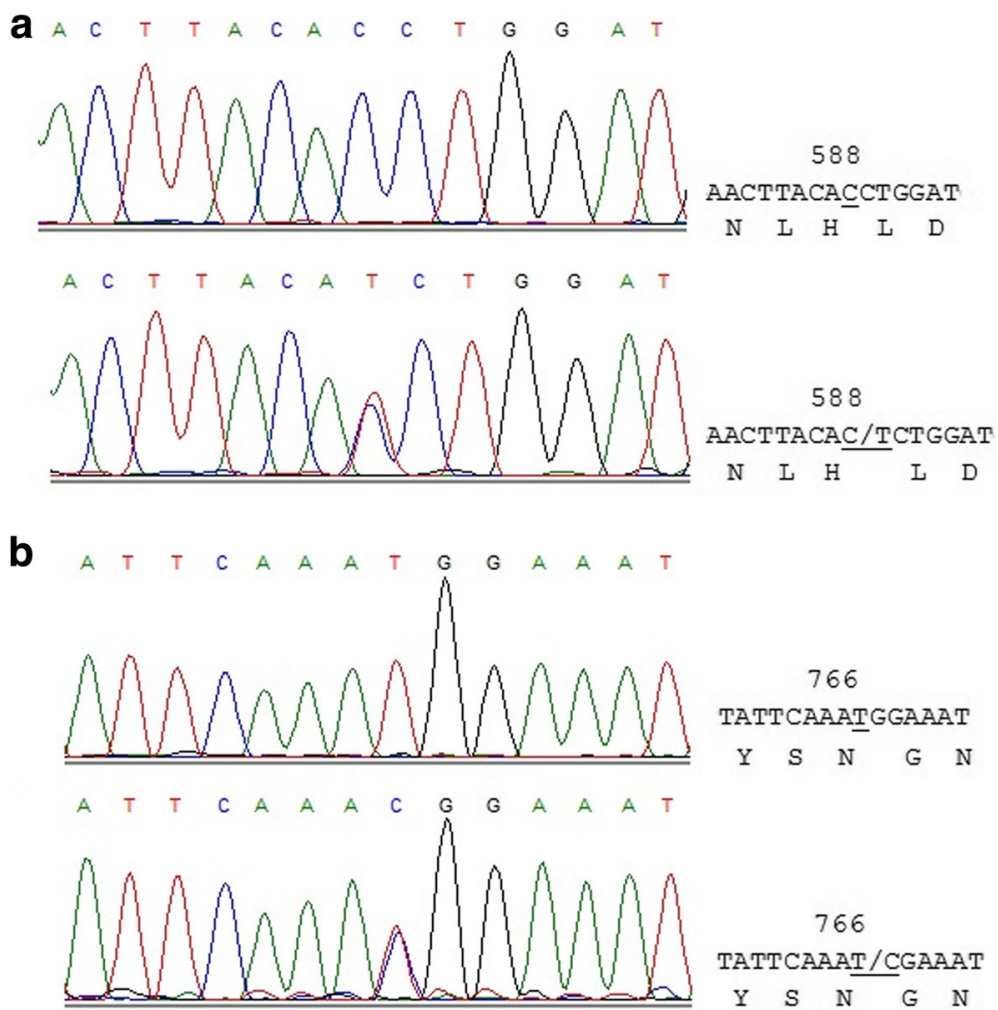

Fig. 1 DNA sequencing results. a Partial nucleotide sequence of exon 6 in the region surrounding codon 588 (rs6194). b Partial nucleotide sequence of exon 9 in the region surrounding codon 766 (rs6196) 
Table 3 Genotypic distributions and allelic frequencies of rs6194 in two groups

\begin{tabular}{cllll}
\hline SNP & $\begin{array}{l}\text { HAPE- } p \\
n=132(\%)\end{array}$ & $\begin{array}{l}\text { HAPE-r } \\
n=132(\%)\end{array}$ & OR (95\% Cl) & $P$ value \\
\hline Genotype & & & \\
CC & $125(0.947)$ & $112(0.848)$ & & \\
CT & $7(0.053)$ & $20(0.152)$ & $3.180(1.299-7.825)$ & 0.008 \\
$T$ & $0(0.00)$ & $0(0.00)$ & & \\
Allele & & & & \\
C & $257(0.973)$ & $244(0.924)$ & $3.009(1.250-7.244)$ & 0.01 \\
$T$ & $7(0.027)$ & $20(0.076)$ & & \\
\hline
\end{tabular}

HAPE- $p$ high-altitude pulmonary edema patients, HAPE-r high-altitude pulmonary edema resistant, $O R$ odds ratio

accumulation of inflammatory cells in multiple organs and elevated serum levels of cytokines were found in mice after short-term exposure to low oxygen concentrations [11-16]. These studies indicate that high altitude induces inflammation, which contributes to the development of HAPE. Anti-inflammatory agents are useful for prevention and treatment of HAPE [17].

Glucocorticoids regulate a broad spectrum of physiologic functions and play an important role in the regulation of inflammatory reactions. The effects of GCs are mediated by GR, which regulates the expression of glucocorticoid-responsive genes $[6,18]$. Variations in NR3C1 gene may contribute to GC responses, and a few rare genetic mutations in NR3C1 have been found to substantially diminish GR function [7]. In the current study, we sequenced most exons of NR3C1 gene and found heterozygous substitutions at codon 588 (rs6194) in exon 6 and 766 (rs6196) in exon 9 of NR3C1 gene, both of them are the synonymous codon substitutions. The genotypic distributions and allelic frequencies of NR3C1 SNP rs6194 were significantly different in two groups $(P<0.05)$. The frequencies of the $C$ allele were significantly higher in the HAPE group than in the control group. There were no differences in genotypic and

Table 4 Genotypic distributions and allelic frequencies of rs6196 in two groups

\begin{tabular}{cllll}
\hline SNP & $\begin{array}{l}\text { HAPE- } p \\
n=133(\%)\end{array}$ & $\begin{array}{l}\text { HAPE-r } \\
n=135(\%)\end{array}$ & OR (95\% Cl) & $P$ value \\
\hline Genotype & & & \\
$T$ & $118(0.887)$ & $109(0.807)$ & & \\
TC & $15(0.113)$ & $26(0.193)$ & $1.876(0.944-3.729)$ & 0.07 \\
CC & $0(0.00)$ & $0(0.00)$ & & \\
Allele & & & & \\
T & $251(0.944)$ & $244(0.904)$ & $1.783(0.922-3.448)$ & 0.082 \\
C & $15(0.056)$ & $26(0.096)$ & & \\
\hline
\end{tabular}

HAPE- $p$ high-altitude pulmonary edema patients, HAPE-r high-altitude pulmonary edema resistant, $O R$ odds ratio allelic frequencies in rs6196 polymorphism between the two groups. The rs6194 and rs6196 SNPs are located in the area that contains a ligand-binding domain (LBD), which is important for protein-protein interaction. The potential functional impacts of common SNPs in NR3C1 gene, including rs6194 and rs6196, had been evaluated in COS-1 cells. Compared with wild-type, protein expression levels of GR variants (rs6194 C>T and rs6196 $\mathrm{T}>\mathrm{C}$ ) increased [19].

Several limitations of this study should be pointed out. First, we only sequenced the exons 2 to 9 and did not screen the promoter and exon 1. Second, the SNPs in intron and $5^{\prime}$ and $3^{\prime}$ UTR are valuable and should be genotyped in future studies. Third, a moderate number of participants were enrolled in the study.

\section{Conclusion}

Our study indicates that NR3C1 gene rs6194 polymorphism is correlated with HAPE susceptibility, and the $\mathrm{CC}$ genotype and $\mathrm{C}$ allele might increase the risk of HAPE in Han Chinese. Screening NR3C1 gene polymorphism may help identify subjects susceptible to HAPE and guide them to take prevention measures.

\section{Acknowledgements}

We thank those physicians for sample collection, Dr Jiangxi from the Yushu People's Hospital, Dr Wei Guan and Yuhong Li from the Affiliated Hospital of Qinghai University, and Dr Rili Ge, Feng Tang and Qin Ga from the Research Center for High Altitude Medical Sciences of Qinghai University for help.

\section{Funding}

This work was supported by the Natural Science Foundation of China (No. 81760335), Basic Applied Study Foundation of Qinghai (2016-ZJ-706), and Science and Technology Support Program of Qinghai (2015-SF-124).

Thousand Talents Program and 135 top academic leaders project of Qinghai.

\section{Availability of data and materials}

Yes.

\section{Authors' contributions}

YY designed the study; HD, JZ, ZS, and YL performed the study and analyzed the data. All authors read and approved the manuscript.

Ethics approval and consent to participate

This study was approved by the Ethics Committee of the Medical College of Qinghai University, and every subject signed written consent.

Consent for publication

Yes.

Competing interests

The authors declare that they have no competing interests.

\section{Publisher's Note}

Springer Nature remains neutral with regard to jurisdictional claims in published maps and institutional affiliations.

Received: 24 January 2018 Accepted: 13 March 2018

Published online: 27 March 2018

\section{References}

1. Hackett PH, Roach RC. High-altitude illness. N Engl J Med. 2001;345(2):107.

2. Basnyat B, Murdoch DR. High-altitude illness. Lancet. 2003;361(9373):1967-74. 
3. Schoene RB, Hackett PH, Henderson WR, et al. High-altitude pulmonary edema: characteristics of lung lavage fluid. JAMA. 1986;256(1):63-9.

4. Hartmann G, Tschöp M, Fischer R, et al. High altitude increases circulating interleukin-6, interleukin-1 receptor antagonist and C-reactive protein. Cytokine. 2000;12(3):246-52.

5. Kubo K, Hanaoka M, Hayano T, et al. Inflammatory cytokines in BAL fluid and pulmonary hemodynamics in high-altitude pulmonary edema. Respir Physiol. 1998;111(3):301-10

6. Neeck G, Renkawitz R, Eggert M. Molecular aspects of glucocorticoid hormone action in rheumatoid arthritis. Cytokines Cell Mol Ther. 2002;7(2):61-9.

7. Zalewski G, Wasilewska A, Zoch-Zwierz W, et al. Response to prednisone in relation to NR3C1 intron B polymorphisms in childhood nephrotic syndrome. Pediatr Nephrol. 2008;23(7):1073-8.

8. Gabry AL, Ledoux X, Mozziconacci M, et al. High-altitude pulmonary edema at moderate altitude $(<2,400 \mathrm{~m} ; 7,870$ feet $)$ a series of 52 patients. Chest. 2003;123(1):49-53.

9. Eltzschig HK, Carmeliet P. Hypoxia and inflammation. N Engl J Med. 2011; 364(7):656-65

10. Grocott MP, Martin DS, Levett DZ, et al. Arterial blood gases and oxygen content in climbers on Mount Everest. N Engl J Med. 2009;360(2):140-9.

11. Rosenberger P, Schwab JM, Mirakaj V, et al. Hypoxia-inducible factordependent induction of netrin-1 dampens inflammation caused by hypoxia. Nat Immunol. 2009;10(2):195-202

12. Eckle T, Faigle M, Grenz A, et al. A2B adenosine receptor dampens hypoxiainduced vascular leak. Blood. 2008;111(4):2024-35.

13. Eltzschig HK, Ibla JC, Furuta GT, et al. Coordinated adenine nucleotide phosphohydrolysis and nucleoside signaling in posthypoxic endothelium: role of ectonucleotidases and adenosine A2B receptors. J Exp Med. 2003; 198(5):783-96.

14. Thompson LF, Eltzschig HK, Ibla JC, et al. Crucial role for Ecto-5'Nucleotidase (CD73) in vascular leakage during hypoxia. J Exp Med. 2004; 200(11):1395-405.

15. Eltzschig HK, Abdulla P. Hoffman E, et al. HIF-1-dependent repression of equilibrative nucleoside transporter (ENT) in hypoxia. J Exp Med. 2005; 202(11):1493-505.

16. Zhang C, Qiang Q, Jiang Y, et al. Effects of hypoxia inducible factor-1a on apoptotic inhibition and glucocorticoid receptor downregulation by dexamethasone in AtT-20 cells. BMC Endocr Disord. 2015;15(1):24

17. Tang $E$, Yu C, Luo Y. Dexamethasone for the prevention of acute mountain sickness: systematic review and meta-analysis. Int J Cardiol. 2014;173(2):133-8.

18. Nicolaides NC, Galata Z, Kino T, et al. The human glucocorticoid receptor: molecular basis of biologic function. Steroids. 2010;75(1):1-12.

19. Niu N, Manickam V, Kalari KR, et al. Human glucocorticoid receptor alpha gene (NR3C1) pharmacogenomics: gene resequencing and functional genomics. J Clin Endocrinol Metab. 2009;94(8):3072-84

\section{Submit your next manuscript to BioMed Central and we will help you at every step:}

- We accept pre-submission inquiries

- Our selector tool helps you to find the most relevant journal

- We provide round the clock customer support

- Convenient online submission

- Thorough peer review

- Inclusion in PubMed and all major indexing services

- Maximum visibility for your research

Submit your manuscript at www biomedcentral.com/submit

) Biomed Central 